\title{
Citation Growth Index: An Index to Monitor Researchers' Citation Growth
}

\author{
Manoochehr Karami ${ }^{*}$, Farzaneh Fazli \\ ${ }^{1}$ PhD, Modeling of Non communicable Diseases Research Center, Department of Epidemiology, School of Public Health, \\ Hamadan University of Medical Sciences, Hamadan, Iran \\ ${ }^{2} \mathrm{MSc}$, PhD student in Library and Information Science, Hamedan Branch, Islamic Azad University and Central Library of Hamadan University \\ of Medical Sciences, Hamadan, Iran
}

Key words: Research Evaluation; Citation; Scientometrics; h-Index.

\section{Dear Editor In Chief}

There are a variety of scientific contributions, productivity and impact indicators include h-index, g-index, hg-index and AR index as citation based indicators. ${ }^{1-4}$ It is evidenced both strengths and weaknesses of such indicators in the literature. ${ }^{5,6}$ Majority of the scientific output measures focus on most cited papers. However, no one has considered predictability of researcher's impact during next years and ignore non cited publications.

This work is aimed to quantify growth of the received citations by researchers according to average growth of citations and introduced a simple index called "Citation Growth Index (CGI)". In the following, steps of calculation CGI and estimated citation growth (ECG) are explained using Equations 1 and 2:

Step1: $E C G=[($ Average citation growth value during three last years +1$) \times$ Number of citations in the last year $]+(0.5 \times$ Number of published documents without citations except current year published documents)

\section{*Address for correspondence:}

Dr. Manoochehr Karami, Fahmide, St. Modeling of Noncommunicable Diseases Research Center,Department of Epidemiology, School of Public Health, Hamadan University of Medical Sciences, Hamadan, Iran.

Email: ma.karami@umsha.ac.ir

Tel: +9

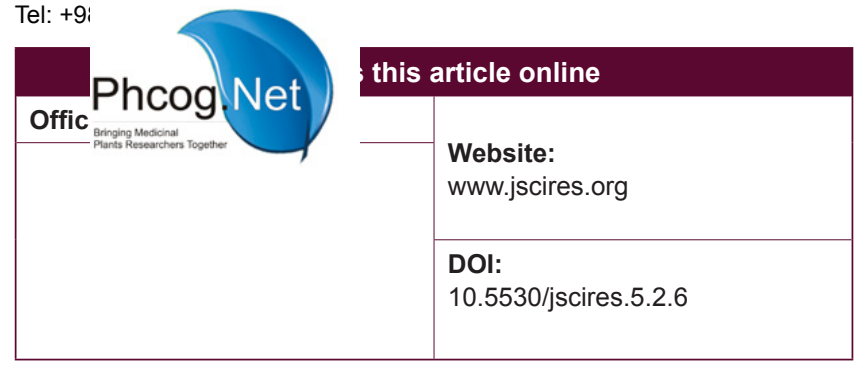

Step2: $C G I=$ Number of citations in current year $-E C G$

Where, average growth value for young researchers can be calculated according to two or one year instead of average of three past years. If CGI for a researcher equals or greater than one, this means the researcher has received expected counts of citations in the specific (current) year. If CGI is less than zero like $-1,-2$ or so on, indicated that researcher has not received expected citations.

Accordingly, CGI may get positive values (Citation+), negative values (Citation-) and zero one, which represents positive growth, negative growth and no growth regarding citations respectively. Required data elements to calculating CGI is summarized in the following dummy Table (Table1).

In conclusion, interested peoples and academic institutions are recommended to monitoring their own researcher's impact and predict expected counts of citations using CGI to represent not only most or highly cited publications but also non cited publications.

\section{CONFLICT OF INTERESTS}

Authors have no conflicts of interests to declare.

\section{REFERENCES}

1. Alonso S, Cabrerizo F, Herrera-Viedma E, Herrera F. hg-index: A new index to characterize the scientific output of researchers based on the h-and g-indices. Scientometrics. 2009;82(2):391-400. http://dx.doi.org/10.1007/s11192-009-0047-5.

2. Egghe L. Mathematical theory of the h-and g-index in case of fractional counting of authorship. Journal of the American Society for Information Science and Technology. 2008;59(10):1608-16. http://dx.doi.org/10.1002/asi.20845. 


\begin{tabular}{|c|c|c|c|c|c|c|c|c|}
\hline Author ID & $\begin{array}{l}\begin{array}{l}\text { Number } \\
\text { last year }\end{array} \\
\text { Year(-3) } \\
2012\end{array}$ & $\begin{array}{l}\text { citations } \\
\text { Year(-2) } \\
2013\end{array}$ & $\begin{array}{l}\text { ring three } \\
\text { Year(-1) } \\
2014\end{array}$ & $\begin{array}{l}\text { Average } \\
\text { citation } \\
\text { growth } \\
\text { value }\end{array}$ & $\begin{array}{l}\text { Number of } \\
\text { citations } \\
\text { in a } \\
\text { specific } \\
\text { year (2015) }\end{array}$ & $\begin{array}{l}\text { Number of } \\
\text { published } \\
\text { documents } \\
\text { without } \\
\text { citation }\end{array}$ & $\begin{array}{l}\text { Estimated } \\
\text { Citation } \\
\text { Growth } \\
\text { (ECG) }\end{array}$ & $\begin{array}{l}\text { Citation } \\
\text { Growth } \\
\text { Index } \\
\text { (CGI) }\end{array}$ \\
\hline
\end{tabular}

3. Hirsch JE. An index to quantify an individual's scientific research output. Proceedings of the National academy of Sciences of the United States of America. 2005;102(46):16569-72. http://dx.doi.org/10.1073/pnas.0507655102; PMid:16275915 PMCid:PMC1283832.

4. Jin B, Liang L, Rousseau R, Egghe L. The R-and AR-indices: Complementing the h-index. Chinese science bulletin. 2007;52(6):855-63. http://dx.doi.org/10.1007/s11434-007-0145-9.
5. Harzing A-W. Reflections on the h-index. See http://www. harzing. com/pop_hindex. htm. 2008.

6. Maabreh M, Alsmadi IM. A Survey of impact and citation indices: Limitations and issues. International Journal of Advanced Science and Technology. 2012;40:35-53. 